\title{
Medical schools as agents of change: socially accountable medical education
}

\section{Richard B Murray MB BS, MPHTM, FACRRM Dean and Head of School \\ Sarah Larkins MB BS, MPHTM, PhD, Associate Professor General Practice and Rural Medicine \\ Heather Russell BMedSci(Hons), MB BS Medical Student (currently, Intern, Cairns Base Hospital) \\ Shaun Ewen BAppSc(Physio) MMIL, DEd, \\ Associate Dea \\ (Indigenous Development)}

David Prideaux

BA(Hons), MEd, PhD,

Emeritus Professor of

Medical Education ${ }^{3}$

1School of Medicine and Dentistry, James Cook University, Townsville, QLD.

2 Faculty of Medicine, Dentistry and Health Science, University of Melbourne, Melbourne, VIC

3 School of Medicine, Flinders University, Adelaide, SA.

richard.murray@ jcu.edu.au

doi: 10.5694/mjall.11473

\section{An abridged version of this article appeared in the printed journal -} download pdf

Series Guest Editor Jennifer J Conn FRACP, MClinEd, BSc(Hons)

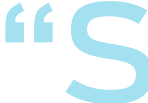

ocial accountability" for medical schools was defined by the World Health Organization in 1995 as:

the obligation to direct their education, research and service activities towards addressing the priority health concerns of the community, region, and/or nation they have a mandate to serve. The priority health concerns are to be identified jointly by governments, health care organizations, health professionals and the public. ${ }^{1}$

The movement towards greater social accountability in medical education has been gathering momentum. ${ }^{2-6}$

Ensuring that medical education reflects and is responsive to the priority health care needs of communities is becoming a focus area for reform on an international level. ${ }^{3,7,8}$ Low-income countries, particularly those in subSaharan Africa, face huge absolute deficits in the number of doctors, nurses, midwives and community health workers required to provide essential health care. ${ }^{9}$ High-income countries also struggle to afford access to health care for all in the context of ageing populations, an increasing range of technological interventions and unsustainable cost drivers. ${ }^{10}$ The rural-urban gradient in health care access is a universal challenge, as is the imperative to meet the needs of vulnerable and underserved groups. ${ }^{11,12}$

Medical schools in Australia and elsewhere, charged with the responsibility of producing the doctors of tomorrow, have been criticised for being more concerned with institutional prestige, biomedical research competitiveness and producing graduates for narrow specialist careers. Medical school recruits are mostly from affluent backgrounds and urban areas, and priority community needs have not always been well reflected in the medical curriculum. Although clinical learning is in a process of change, with tertiary hospitals no longer being the sole provider of clinical education, in many ways the traditions and cultures of these hospitals still dominate. ${ }^{13-17}$ Moreover, many schools are not deeply engaged with the broader health care sector or with community organisations, and are often not involved in postgraduate vocational education. ${ }^{18,19}$

For medical educators, policymakers, community leaders or health professionals seeking to establish medical schools with social accountability aims (or to encourage existing medical schools to give greater priority to social accountability), there is much that can be learned from the experience of others. As might be expected, it is in those places where the gap between the community's needs for health care and the availability of doctors has been greatest that innovation in medical education has flourished.

Here, we explore Australian developments in medical education in response to priority health concerns (i) in
Summary

- Medical education reform can make an important contribution to the future health care of populations. Social accountability in medical education was defined by the World Health Organization in 1995, and an international movement for change is gathering momentum.

- Priority community needs are generally not well reflected in existing medical curricula. Medical schools have often been concerned more with prestige, research competitiveness and training doctors for narrow specialist careers in urban areas.

- Orthodoxies in medical education have been challenged where the gap between a community's health care needs and the availability of doctors has been greatest notably in rural areas and, in Australia, in Aboriginal communities.

- At a time of growing crisis in health care systems, the need to focus on addressing health inequalities and delivering effective, affordable, people-centred health care is more important than ever.

- While change can be enabled with policy levers, such as funding tied to achieving equity outcomes and systems of accreditation, medical schools and students themselves can lead the transformation agenda. An international movement for change and coalitions of medical schools with an interest in socially accountable medical education provide a "community of practice" that can drive change from within.

rural and remote areas and (ii) in Aboriginal and Torres Strait Islander peoples. There is now a growing international community of practice available to those seeking to drive change and deliver on the promise of the movement towards greater social accountability in medical education.

\section{Lessons from Australian rural settings}

The geographic maldistribution of doctors is a worldwide phenomenon. Orthodoxies in medical education have been strongly challenged by rural communities and rural practitioners. In Australia in 2006, the ratio of population to doctors varied from 240 people for every medical practitioner in major cities to 588 people per medical practitioner in outer regional areas and 1041 in remote areas. ${ }^{12}$ Health status is in inverse proportion to this, even taking into account the poor health status of the Indigenous population. ${ }^{20}$

\section{Factors influencing rural practice}

From early observational studies, the evidence has accumulated that student selection is a key strategy for producing 
doctors who are more likely to choose rural careers. For example, rural-origin students are two to three times more likely than their city counterparts to practise in rural areas after graduation. ${ }^{21,22}$ Similarly, doctors graduating from regionally based medical schools are more likely to practise in rural areas. ${ }^{11,21}$ Bonded scholarships and other returnof-service obligations have an impact, as does the availability of rural-based postgraduate training. ${ }^{23}$ While linear associations are difficult to disentangle in what is typically a set of complex interventions and observational studies, it seems likely that a curriculum with a rural orientation, combined with rural clinical placements for students, also has a positive impact. ${ }^{24-26}$

Political advocacy from the rural sector and accumulating evidence from academic research, reviews and collective experience ${ }^{11,24}$ has helped policymakers implement programs that produce a rural medical workforce. As a country, Australia has exercised notable leadership in this regard, with the range of policy interventions now including:

- bonded medical rural scholarships and bonded medical places;

- rural medical placement support;

- rural clinical school campuses of metropolitan programs;

- wholly regionally based medical schools;

- selection targets for rural-origin students; and

- university-based, rural-health clubs for students. ${ }^{27,28}$

\section{Establishing symbiotic relationships}

There are many principles from medical education in the rural context that can be applied more generally - particularly in places where resources are thin and health care needs unmet. For example, an important principle applied in effective rural programs has been that of "symbiosis", whereby universities and health services build mutually reinforcing relationships. Students receive good teaching and in turn make an authentic contribution to the work of the health service. The university presence brings infrastructure, advocacy and recognition to the rural health service. $^{29,30}$ This support reduces the risk that busy rural health services run in taking on a teaching workload, which might not deliver the future rural workforce that is the essential rationale.

Under this principle of symbiosis, there is an expectation that students will undertake extended placements in rural settings, rather than visit for short rotations or for some form of "medical tourism". Furthermore, there is evidence that students undertaking long placements in rural settings perform better in medical school examinations. ${ }^{29,30}$

As part of the symbiotic relationship between universities and health services, universities will work with health services to achieve their priorities of attracting a future workforce. From a community perspective, it is obvious that priority should be given to long-term rural placements for those students who demonstrate a genuine vocational interest in rural practice - that is, "merit" from the community perspective.

\section{Funding requirements}

There are lessons for policymakers too. The success of rural medical education reforms in Australia would not have been possible without government acceptance that providing clinical teaching in distributed, community-based models requires significant resources for accommodation, infrastructure and staffing. The substantial injection of federal government health-sector funding through the Rural Clinical School and University Department of Rural Health programs both enabled and helped drive these reforms. Programs were structured to ensure that funds were directed towards those activities known to deliver a future rural workforce, rather than diverted to other university priorities.

\section{Experience from the Aboriginal health context}

In spite of having much higher levels of morbidity, infant mortality and a lower expectation of life at birth, Aboriginal and Torres Strait Islander peoples (Indigenous Australians) have poorer access to medical care than the general population. ${ }^{31,32}$ Doctors have often been poorly equipped to provide culturally safe and technically appropriate care. ${ }^{33}$ Moreover, Indigenous Australians are grossly underrepresented in medical careers: the first Indigenous doctor in Australia graduated as recently as 1983. In contrast, the first Maori doctor in New Zealand graduated in 1899 and the first Papua New Guinean doctor in 1951. The situation in Australia is improving with the Medical Deans of Australia and New Zealand reporting that, in September 2011, there were 153 Indigenous doctors, and 218 Indigenous medical students enrolled in Australian medical schools (Australian Indigenous Doctors' Association www.aida.org.au/pdf/Numbersofdoctors.pdf).

\section{Aboriginal community leadership in health}

Aboriginal leadership in health, growing out of the establishment of Aboriginal community-controlled health services (ACCHSs) in the 1970s and 80s, has been a critical factor in health professional education reform. The landmark National Aboriginal Health Strategy (NAHS) report in 1989 set out a comprehensive blueprint for change, including better education for all health professionals, as well as the imperative to recruit and train more Indigenous doctors and nurses. ${ }^{33}$ All health professionals working with Indigenous peoples should not only provide treatment, they also need skills in advocacy to assist individuals and communities in crises, and with housing, legal, employment and other issues. The NAHS report found that, in the teaching of health professionals, scant attention had been paid to the context of Aboriginal history to Aboriginal health and that, as a result, there were problems with "unrealistic expectations ... and intolerance based on lack of understanding". ${ }^{33}$

\section{Anticipating socially accountable medical education}

The NAHS report, driven strongly by community leaders, anticipated many of the contemporary themes in socially accountable medical education: curriculum reform to "reflect a primary health care approach [and the] linkages between community empowerment, social justice, equity 
and health"; the need for formal clinical placements in communities and in community-run health services; and special measures needed to support Aboriginal students to undertake tertiary studies. ${ }^{33}$ The momentum from the NAHS led to partnerships between peak Aboriginal health bodies (National Aboriginal Community Controlled Health Organisation and Australian Indigenous Doctors' Association), the medical colleges (Royal Australian College of General Practitioners and Australian College of Rural and Remote Medicine), and medical schools (the then Committee of Deans of Australian Medical Schools). These partnerships produced a national Indigenous health curriculum plan for general practice in 1994, and a national curriculum framework for medical schools in 2004, both of which are now reflected in accreditation documents. ${ }^{34}$

\section{Curriculum development and student placements}

There are instructive lessons for curriculum development in the Indigenous health context. For instance, the progress made in formal curriculum development in Indigenous health can be undermined if the "hidden curriculum" is not identified - in both the classroom and in health care settings. ${ }^{35}$ Experiences of subtle and overt discrimination and racism have a negative impact on learning for Indigenous students, who can find the experience of medical school alienating. ${ }^{36}$

The importance of quality practical experience for students in community-centred models of health care delivery is a key consideration; there is a limit to what can be achieved in the classroom. This issue is emerging as a key rate-limiting step in medical schools' efforts to prepare graduates to work effectively with Indigenous patients and communities. Many of the roughly 140 ACCHSs across the country provide such placements in a comprehensive primary health care model. However, given funding, staff and capacity constraints and a necessary focus on providing care to communities, diverting resources to support student placements can be a challenge. Like other community-based care environments (and unlike tertiary teaching hospitals), ACCHSs have generally not been designed nor resourced as training facilities for learners. The demand for quality "immersion" experience in ACCHSs comes not only from the 18 Australian medical schools, but also from students of other health professions, junior doctors, and general practice and other specialty registrars.

As in the rural setting, the socially accountable approach for a medical school in this context is to build an authentic partnership with local ACCHSs and to develop arrangements that have reciprocal benefits in workforce, service, research and other community-identified priorities. This includes providing or brokering the human and capital resources required to make student placements work. University clinical academics directly participating in clinical services in an ACCHS can be part of this engagement. Well planned and coordinated placements then increase, rather than drain, the resources available to communities that need health care most.

\section{The contribution of students}

Increasing diversity of medical student backgrounds and career intentions is an important factor in medical education reform. Medical students can advocate for their education to prepare them for careers in all settings, including with vulnerable and underserved communities. As the "consumers" of medical education, students are the only people to fully experience medical curricula and are well placed to give advice about aligning curricula with educational needs.

To become effective as "enlightened agents of change", students require more than medical knowledge and skills. Abilities in population research, activism and health policy are also important. ${ }^{37}$ Students (including Indigenous students) must learn and practise "parrhesia" — the ability and the duty to speak the truth fearlessly for the common good. ${ }^{38,39}$

\section{Challenges for rural and Indigenous medical students}

Two developments - the establishment of regionally based medical schools, and the recruitment of Indigenous students and students from rural areas - are helping to broaden medical student diversity in Australia, and deliver medical graduates into areas of workforce shortage. However, this is not without its own challenges: the barriers that rural-origin and Indigenous students often face in accessing medical education need to be anticipated. The requirement to physically relocate and live independently may force students to take on substantial paid employment or to seek scholarships with return-of-service obligations. ${ }^{40}$ For some, disconnection from support networks can result in social isolation and poor social and emotional wellbeing. ${ }^{41}$ While scholarships and government financial support can help lessen the economic burden for those who are able to access them, medical schools, working with the student body, need to be prepared to cope with problems arising from social and cultural isolation.

\section{Rural-health clubs}

University rural-health clubs are an example of an initiative that attempts to address social isolation as well as nurture student interest in rural health and rural careers. Student-led rural-health clubs were first established in the early 1990s, as part of a "rural counterculture" within the orthodoxy of medical schools. ${ }^{42}$ With federal government funding support, multiprofessional rural-health clubs have been established at 29 Australian universities and are represented by the National Rural Health Students' Network (NRHSN). ${ }^{43}$

These clubs have been important agents of change in medical education. Extracurricular educational and social activities provide positive rural experiences, promote careers in rural health and assist in recruitment of students from rural secondary schools. ${ }^{44}$ Rural-health clubs exercise influence within medical curricula through educational committee membership and direct representation around issues such as rural clinical placements and interprofessional education. At the national level, the NRHSN provides leadership and advocacy, along with regular forums for students to meet with policymakers. 
Strategies of the Training for Health Equity Network (THEnet) (www.thenetcommunity.org)

- Health and social needs of targeted communities guide education, research and service programs

- Social accountability is demonstrated in action through a "whole school" approach

- Students are recruited from the communities with the greatest health care needs

- Programs are located within or in close proximity to the communities they serve

- Medical education is embedded in the health system and takes place in the community and clinics instead of predominantly in university and hospital settings

- Curriculum integrates basic and clinical sciences with population health and social sciences; and early clinical contact increases the relevance and value of theoretical learning

- Pedagogical methods are student-centred, problem- and service-based and supported by information technology

- Community-based practitioners are recruited and trained as teachers and mentors

- Health system personnel are partners in producing graduates with locally relevant competencies

- Faculty and programs emphasise and model commitment to public service

\section{Global collaborations}

There are increasing opportunities to engage with an international "community of practice" in socially accountable medical education. Australian medical schools at James Cook University, Queensland, and Flinders University, South Australia, are part of an international collaboration of medical schools from the Philippines, South Africa, Canada, Cuba, Venezuela, Nepal, Sudan, Belgium and the United States. The Training for Health Equity Network (THEnet) involves 11 medical schools committed to socially accountable health education (Box). The collaboration has developed, piloted and evaluated a common evaluation framework to help this collaboration and other medical schools work to implement socially accountable medical education - "out of the ivory tower and into the community" ${ }^{45}$

\section{Conclusions}

At a time of a growing crisis in health care systems, the need for a focus on addressing health inequalities and the delivery of effective, affordable, people-centred health care is more important than ever. Socially accountable medical education is a strategy that can make an important contribution. Experiences from medical education reform in the rural and Aboriginal community contexts and from underserved communities around the world have broader application. There are many practical insights that can be shared on the "how-to" of authentic community partnerships, targeted student selection, curriculum reform, communitybased learning, efforts to harness and develop student altruism and leadership, and other strategies.

Policy levers to enable and drive change include funding that is tied to achievement of equity outcomes and systems of medical school accreditation. However, medical schools must themselves commit to do more than merely produce graduates who possess a set of clinical abilities and knowledge of foundation science. An international movement for change, and growing coalitions among medical schools with an interest in socially accountable medical education, provide a community of practice that can help to lead change from within.

Competing interests: No relevant disclosures.

Provenance: Commissioned; externally peer reviewed.

1 Boelen C, Heck J. Defining and measuring the social accountability of medical schools. Geneva: World Health Organization, 1995 (Unpublished document WHO/HRH/95.7, available on request from Division of Organization and Management of Health Systems, World Health Organization, 1211 Geneva 27, Switzerland.)

2 Boelen C. A new paradigm for medical schools a century after Flexner's report. Bull World Health Organ 2002; 80: 592-593.

3 Boelen C, Woollard B. Social accountability and accreditation: a new frontier for educational institutions. Med Educ 2009; 43: 887-894.

4 Frenk J, Chen L, Bhutta Z, et al. Health professionals for a new century: transforming education to strengthen health systems in an interdependent world. Lancet 2010; 376: 1923-1958.

5 Ho K, Buote D, Jarvis-Selinger S, et al. Achieving social accountability through interprofessional collaboration: the Canadian medical schools experience. JInterprof Care 2008; 22 Suppl 1: 4-14.

6 Pálsdóttir B, Neusy AJ, Reed G. Building the evidence base: networking innovative socially accountable medical educational programs. Educ Health (Abingdon) 2008; 21: 177. http://www.educationforhealth.net/ publishedarticles/article_print_177.pdf (accessed Apr 2012).

7 Association of Faculties of Medicine of Canada. The future of medical education in Canada (FMEC): a collective vision for MD education. Ottawa: AFMC, 2010. http://www.afmc.ca/future-of-medical-education-in-canada/ medical-doctor-project/pdf/collective_vision.pdf (accessed Apr 2012).

8 Skochelak S. A decade of reports calling for change in medical education: what do they say? Acad Med 2010; 85 (9 Suppl): S26-S33.

9 World Health Organization. The world health report 2006: working together for health 2006. Geneva: WHO, 2006. http://www.who.int/whr/2006/en/ index.html (accessed Apr 2012).

10 Australian Government Department of Health and Ageing. Building a 21st century primary health care system: Australia's first national primary health care strategy. Canberra:DoHA, 2010. http://www.health.gov.au/internet/ yourhealth/publishing.nsf/Content/report-primaryhealth (accessed Apr 2012).

11 World Health Organization. Health Workforce. Increasing access to health workers in remote and rural areas through improved retention. Global policy recommendations. Geneva: WHO, 2010. http://www.who.int/hrh/retention/ guidelines/en/index.html (accessed Apr 2012).

12 Australian Government Department of Health and Ageing. Report on the audit of health workforce in rural and regional Australia, April 2008. Canberra: Commonwealth of Australia, 2008. http://www.health.gov.au/internet/ main/publishing.nsf/Content/4F3A981914316A11CA257434008189EC/\$File/ ruraud.pdf (accessed Apr 2012).

13 Kaufman A. Measuring the social responsiveness of medical schools: a case study from New Mexico. Acad Med 1999; 74 (8 Suppl): S69-S74.

14 Heath C, Stoddart C, Green H. Parental backgrounds of Otago medical students. N Z Med J 2002; 115: U237.

15 Dhalla I, Kwong J, Streiner D, et al. Characteristics of first-year students in Canadian medical schools CMAJ 2002; 166: 1029-1035.

16 Block S, Chiarelli N, Peters A, et al. Academia's chilly climate for primary care. JAMA 1996; 276: 677-682.

17 Hewett D, Gallois C, Ward M, et al. Intergroup communication between hospital doctors: implications for quality of patient care. Soc Sci Med 2009; 69: 1732-1740.

18 Rourke J. Social accountability in theory and practice. Ann Fam Med 2006; 4 Suppl 1: S45-S48; discussion S58-S60.

19 Mullan F, Chen C, Petterson S, et al. The social mission of medical education: ranking the schools. Ann Intern Med 2010; 152: 804-811.

20 Australian Institute of Health and Welfare. Rural, regional and remote health: indicators of health system performance. Canberra: AlHW, 2008. (AlHW Cat. No. PHE 103.) http://www.aihw.gov.au/publication-detail/?id=6442468150 (accessed Apr 2012).

21 Dunbabin J, Levitt L. Rural origin and rural medical exposure: their impact on the rural and remote medical workforce in Australia. Rural Remote Health [internet] 2003; 3: 212. Epub 2003 Jun 25.

22 Hsueh W, Wilkinson T, Bills J. What evidence-based undergraduate interventions promote rural health? N Z Med J 2004; 117: U1117. http:// www.nzma.org.nz/journal/17-1204/1117/ (accessed Apr 2012).

23 Gray JD, Steeves LC, Blackburn JW. The Dalhousie University experience of training residents in many small communities. Acad Med 1994; 69: 847-851. 
24 Grobler L, Marais BJ, Mabunda SA, et al. Interventions for increasing the proportion of health professionals practising in rural and other underserved areas. Cochrane Database Syst Rev 2009; (1):CD005314.

25 Strasser R, Neusy AJ. Context counts: training health workers in and for rural and remote areas. Bull World Health Organ 2010; 88: 777-782.

26 Blue AV, Chessman AW, Geesey ME, et al. Medical students' perceptions of rural practice following a rural clerkship. Fam Med 2004; 36: 336-340.

27 Sen Gupta TK, Murray RB, McDonell A, et al. Rural internships for final year students: clinical experience, education and workforce. Rural Remote Health [internet] 2008; 8: 827. Epub 2008 Feb 13.

28 Chater A. Looking after health care in the bush. Aust Health Rev 2008; 32: 313-318.

29 Prideaux D, Worley P, Bligh J. Symbiosis: a new model for medical education. Clin Teach 2007; 4: 209-212.

30 Worley P. Esterman D. Prideaux D. Cohort analysis of examination performance of undergraduate medical student learning in community settings. BMJ 2004; 328: 207-209.

31 Australian Institute of Health and Welfare. The health and welfare of Australia's Aboriginal and Torres Strait Islander people: an overview 2011. Canberra: AlHW, 2011. (AlHW Cat. No. IHW 42.) http://www.aihw.gov.au/ publication-detail/?id=10737418989 (accessed Apr 2012).

32 Australian Institute of Health and Welfare. Access to health and services for Aboriginal and Torres Strait Islander people. Canberra: AlHW, 2011. (AlHW Cat. No. IHW 46.) http://www.aihw.gov.au/publication-detail/?id=10737418966 (accessed Apr 2012).

33 Office of Aboriginal and Torres Strait Islander Health. A National Aboriginal Health Strategy. Canberra: OATSIH, 1989. http://www.health.gov.au/internet/ main/publishing.nsf/Content/health-oatsih-pubs-NAHS1998 (accessed Ap 2012).

34 Committee of Deans of Australian Medical Schools, Australian Indigenous Doctors' Association. CDAMS Indigenous Health Curriculum Framework. Melbourne: ONEMDA and Koorie Press, 2004. http://www.limenetwork. net.au/files/lime/cdamsframeworkreport.pdf (accessed Apr 2012).
35 Hafferty F, Franks R. The hidden curriculum, ethics teaching, and the structure of medical education. Acad Med 1994; 69: 861-871.

36 Garvey G, Rolfe I, Pearson S, et al. Indigenous Australian medical students' perceptions of their medical school training. Med Educ 2009; 43: 1047-1055.

37 Cha S, Ross J, Lurie P, et al. Description of a research-based health activism curriculum for medical students. J Gen Intern Med 2006; 21: 1325-1328.

38 Papadimos TJ, Murray SJ. Foucault's "fearless speech" and the transformation and mentoring of medical students. Philos Ethics Humanit Med 2008; 3: 12.

39 Ewen SC. Unequal treatment: the possibilities of and need for indigenous parrhesiastes in Australian medical education. J Immigr Minor Health 2011; 13: 609-615.

40 Parliament of Australia. Senate standing committee on rural and regional affairs and transport. Inquiry into rural and regional access to secondary and tertiary education opportunities. Canberra: The Senate, 2009. http:// www.aph.gov.au/Parliamentary_Business/Committees/Senate Committees?url=rrat_ctte/rural_and_regional_education/index.htm (accessed Apr 2012).

41 King S, Garrett R, Wrench A, et al. The loneliness of relocating: does the transition to university pose a significant health risk for rural and isolated students? Proceedings of the 14th Pacific Rim First Year in Higher Education Conference; 2011 Jun 28 - Jul 1; Freemantle, Australia. http://www.fyhe. com.au/past_papers/papersll/FYHE-2011/content/pdf/16B.pdf (accessed Apr 2012).

42 Kamien M. Rural student clubs and the social responsibility of medical schools. Aust J Rural Health 1996; 4: 237-241.

43 National Rural Health Students' Network. Rural health clubs [website] 2011. http://www.nrhsn.org.au/site/index.cfm?display=39703 (accessed Apr 2012)

44 Turner J, Scott L. University rural health clubs: nurturing the future Australian rural workforce. Rural Remote Health [internet] 2007; 7: 649. Epub 2007 Jul 5.

45 THEnet: Training for Health Equity Network. Social accountability in action. THEnet's evaluation framework for socially accountable health professional education. Version 1.0. Monograph 1. Brussels: The Training for Health Equity Network, 2011. http://thenetcommunity.org/files/articles/Monograph\% 20print\%20quality\%20feb\%201.pdf (accessed Apr 2012). 